Article

\title{
Optimization of Ultrasonic-Assisted Extraction of Total Phenolics from Citrus aurantium L. Blossoms and Evaluation of Free Radical Scavenging, Anti-HMG-CoA Reductase Activities
}

\author{
Kexin Hao ${ }^{1,2}$, Wenzhong Hu ${ }^{1,2, *}$, Mengyang Hou ${ }^{2,3}$, Duo Cao ${ }^{4}$, Yu Wang ${ }^{1,2}$, Qingxin Guan ${ }^{1,2}$, \\ Xiufu Zhang ${ }^{1,2}$, Aosheng Wang ${ }^{1,2}$, Jiaoxue $\mathrm{Yu}^{1,2}$ and Binmei Guo ${ }^{1,2}$ \\ College of Life Science, Dalian Nationalities University, Dalian 116600, China \\ 2 Key Laboratory of Biotechnology and Bioresources Utilization, Ministry of Education, Dalian 116600, China \\ 3 School of Life Science and Biotechnology, Dalian University of Technology, Dalian 116024, China \\ 4 College of Life Science, Northwest University, Xi'an 710069, China \\ * Correspondence: hwz@dlnu.edu.cn; Tel.: +86-135-9116-2665
}

Received: 9 May 2019; Accepted: 21 June 2019; Published: 26 June 2019

\begin{abstract}
The objective of this study was to develop an ultrasonic-assisted procedure for the extraction of total phenolics from Citrus aurantium L. blossoms (CAB) and evaluate the free radical scavenging activity and anti-HMG-CoA reductase activity of the total phenolics. In this work, a Box- Behnken design based on single-factor experiments was used to explore the optimum extraction process. Under the optimum conditions (extraction solvent $70.31 \%$ ethanol, extraction temperature $61.94{ }^{\circ} \mathrm{C}$, extraction time $51.73 \mathrm{~min}$, and liquid-to-solid ratio $35.63 \mathrm{~mL} / \mathrm{g}$ ), the extraction yield of total phenolics was $95.84 \mathrm{mg}$ gallic acid equivalents (GAE)/g dry matter (DM), which was highly consistent with the theoretical value ( $96.12 \mathrm{mg} \mathrm{GAE} / \mathrm{g} \mathrm{DM}$ ). The higher contents of total phenolics and five main phenolic compounds obtained from the optimized ultrasonic-assisted extraction (UAE) proved its efficiency when compared with conventional heat reflux extraction (HRE). The total phenolic extract showed excellent free radical scavenging properties against 1,1-diphenyl-2-picrylhydrazyl radical (DPPH.), 2,2' -azino-bis-(3-ethylbenzthiazoline-6-sulphonic acid) radical (ABTS $\left.{ }^{+} \cdot\right)$, hydroxyl radical $(\cdot \mathrm{OH})$ and superoxide anion radical $\left(\cdot \mathrm{O}_{2}{ }^{-}\right)$, with $\mathrm{IC}_{50}$ values of $197.007,83.878,218.643$, and $158.885 \mu \mathrm{g} / \mathrm{mL}$, respectively; the extracts also showed good inhibition of $\beta$-hydroxy- $\beta$-methylglutaryl-CoA reductase (HMG-CoA reductase) activity, with an $\mathrm{IC}_{50}$ value of $117.165 \mu \mathrm{g} / \mathrm{mL}$. Total phenolics from CAB could be a potential source of natural free radical scavenger and HMG-CoA reductase inhibitor.
\end{abstract}

Keywords: Citrus aurantium L. blossoms; total phenolics; ultrasonic-assisted extraction; Box-Behnken design; free radical scavenging activity; anti-HMG-CoA reductase activity

\section{Introduction}

Free radicals, atoms or groups containing unpaired electrons, are fairly active, which is essential for any physiological metabolism of an organism [1]. As is well known, an organism itself has the ability to balance free radicals, but the risk of several serious diseases will increase if the organism cannot get rid of excess free radicals. Modern medical studies have demonstrated that free radicals can lead to DNA, protein and lipid oxidative damage and have a direct relationship with cancer, cardiovascular diseases, Alzheimer's and Parkinson's disorders [2-7]. Dietary supplementation of exogenous free radical scavengers, is associated with a reduced incidence of those frightening diseases. Despite the enormous development of chemical synthesis, many excellent natural free radical scavengers with fewer side effects from edible or medicinal plants have been successfully exploited over the past several 
years [8]. Plants are rich in various bioactive compounds, in which phenolics have attracted increasing attention due to their pre-eminent free radical scavenging property.

In recent years, the morbidity and mortality of cardiovascular and cerebrovascular diseases have risen dramatically due to the improvement of people's living standards [9]. These diseases have very high correlation with hyperlipidemia, mainly manifesting as high levels of cholesterol in the blood [10]. A key regulatory enzyme, 3-hydroxy-3-methylglutaryl-coenzyme A reductase (HMG-CoA reductase), has a significant impact on cholesterol biosynthesis [11]. Hence, an effective method for reducing cholesterol level is to inhibit HMG-CoA reductase activity. The existing HMG-CoA reductase inhibitors are mainly statin drugs. Unfortunately, other potentially harmful side effects, such as myopathy and liver damage, appear with long-time use of statin drugs [12,13]. Therefore, the screening of novel HMG-CoA reductase inhibitors is urgent.

Citrus aurantium L. belonging to the genus Citrus (Rutaceae), is mainly cultivated in tropical and subtropical areas. Citrus aurantium L. is a well-known medicinal and edible plant in China and has been traditionally used for treatment of obesity, indigestion, chest congestion, bellyache, nausea, and vomiting [14], as well as recently attracting attention for its extensive biological activities including anticancer, antibacterial, antioxidant, antidiabetic, enhancing immunity, and treatment for neurological disorders [15-19]. Citrus aurantium L. blossom (CAB) especially has been popularly consumed in a variety of functional beverages for a long time in China. Recently, $\mathrm{CAB}$ has attracted increasing attention because of its extensive biological activities including anti-complement, anti- inflammatory, anti-tumor, and antioxidant activities [15-17]. In addition, previous studies have shown that CAB is a good source of phenolic compounds. For example, Shen et al. found that the crude polyphenols extracted from $\mathrm{CAB}$ mainly contained neoeriocitrin, eriocitrin, rhoifolin, hesperidin, naringin, rutin, neohesperidin, and hesperetin by LC-MS analysis [15]. Karimi et al. also found that CAB contained pyrogallol, caffeic acid, gallic acid, and syringic acid by RP-HPLC analysis [16]. The phenolic compounds were the major contributors to the beneficial health effects of $\mathrm{CAB}$.

In fact, extraction technology not only has a direct influence on the extraction efficiency of phytochemical components, but also has a profound effect on the biological activities. Karimi et al. researched the effects of solvent type on phenolics and flavonoids contents and anti-tumor, anti-inflammatory, antioxidant activities of $\mathrm{CAB}$ [16]. Yang et al. optimized the extraction process of flavonoids from $C A B$ [18]. Although the optimum conditions for the extraction of polyphenols from $\mathrm{CAB}$ with water as the extraction solvent were studied by Shen et al. [19], the optimized extraction process required a high temperature $\left(90^{\circ} \mathrm{C}\right.$ ) and took a long time (each time for $1 \mathrm{~h}$ ), moreover, according to the result reported by Karimi et al. [16], not only did the aqueous extract exhibit the lowest DPPH. scavenging activity, but the extraction yield of water was the lowest compared with methanolic, and ethanolic extracts. Hence, there is an urgent need to develop a novel and efficient approach to extract phenolic substances from CAB. Compared with conventional solvent extraction methods (cold or warm soaking, decoction, heat reflux, and Soxhlet extraction), ultrasonic-assisted extraction (UAE) is relatively simple, efficient, and practical. UAE can also enhance the biological activities of extracts [20-22]. As a novel technology, UAE has been proposed by many researchers, such as for phenolic compounds from blueberry pomace [23], Oryza sativa L. 'Violet Nori' [24], Brosimum alicastrum leaves [25], and Acer Truncatum leaves [26].

This study was committed to develop an energy-efficient technology for extraction of total phenolics from $\mathrm{CAB}$ by $\mathrm{UAE}$, and the process parameters were optimized through single-factor experiment and Box-Behnken design. In addition, free radical scavenging and anti-HMG-CoA reductase activities of total phenolic extract were evaluated in vitro. 


\section{Results and Discussion}

\subsection{Single-Factor Experimental Analysis}

\subsubsection{Effect of Ethanol Concentration on the Extraction Yield of Total Phenolics}

Aqueous ethanol solution is a most common extraction solvent, which has been extensively used for the extraction of natural products due to its high-efficiency, and eco-friendly and recyclable characteristics. The extraction solvent with proper polarity is vital to the solubility of total phenolics [27]. Different concentrations of ethanol have different polarity, therefore, the effects of ethanol concentrations $(30-80 \%)$ on the extraction yield of total phenolics from CAB were evaluated when controlling for other factors (extraction temperature $45^{\circ} \mathrm{C}$, extraction time $30 \mathrm{~min}$ and liquid-to-solid ratio $30 \mathrm{~mL} / \mathrm{g}$ ). As shown in Figure 1a, the extraction yield of total phenolics significantly improved from $48.95 \pm 1.32$ to $91.58 \pm 1.12 \mathrm{mg}$ GAE/g DM with the increase in ethanol concentration from $30 \%$ to $70 \%$. However, the extraction yield declined with further increase of ethanol concentration. Hence, 70\% ethanol was considered as the optimal extraction solvent.

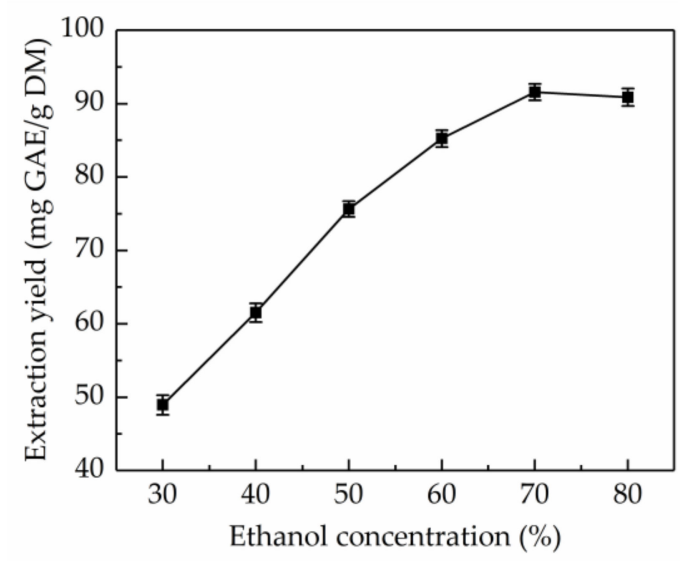

(a)

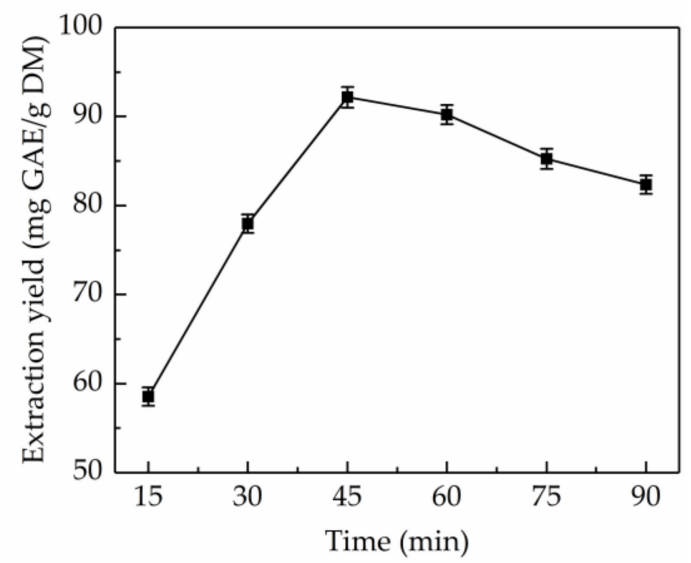

(c)

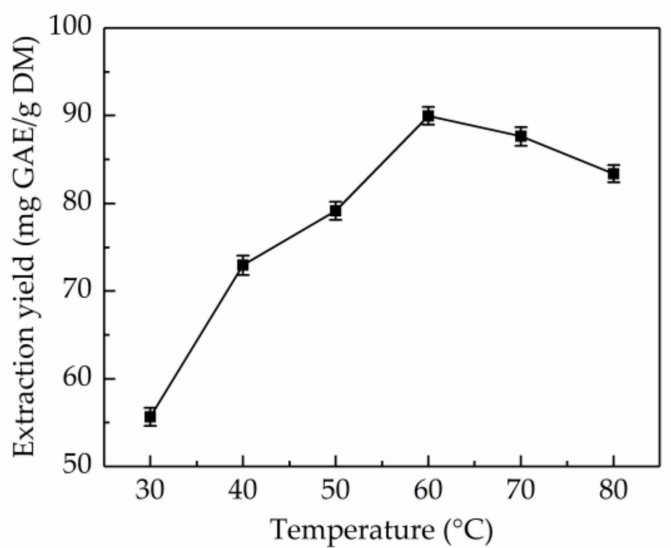

(b)

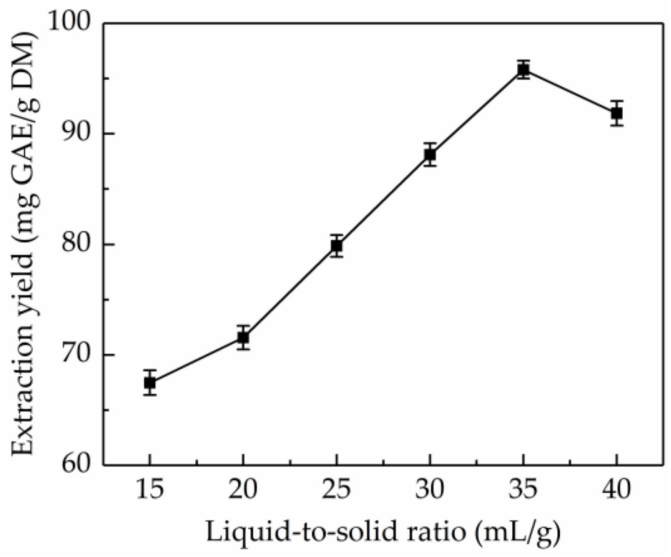

(d)

Figure 1. Effects of ethanol concentration (a), extraction temperature (b), extraction time (c), and liquid-to-solid ratio (d) on the extraction yield of total phenolics.

\subsubsection{Effect of Extraction Temperature on Extraction Yield of Total Phenolics}

In general, the higher the extraction temperature, the higher is the extraction yield, which is due to the fact that molecules move faster at higher temperature, leading to enhanced diffusion and permeation behaviors [28]. However, if the extraction temperature is too high, the heat-sensitive 
components would be destroyed. Hence, to improve extraction yield, extraction temperatures in the range of $30-80{ }^{\circ} \mathrm{C}$ were studied when controlling for other factors (ethanol concentration $70 \%$, extraction time $30 \mathrm{~min}$, and liquid-to-solid ratio $30 \mathrm{~mL} / \mathrm{g}$ ). Figure $1 \mathrm{~b}$ showed that the extraction yield of total phenolics from $\mathrm{CAB}$ obviously increased in the range of $30-60^{\circ} \mathrm{C}$, however, further increase in the extraction temperature resulted in a gradual decrease in the extraction yield. The highest extraction yield of total phenolics $(89.98 \pm 1.01 \mathrm{mg} \mathrm{GAE} / \mathrm{g} \mathrm{DM})$ was obtained at $60{ }^{\circ} \mathrm{C}$. Therefore, $60{ }^{\circ} \mathrm{C}$ was considered as the optimum extraction temperature.

\subsubsection{Effect of Extraction Time on Extraction Yield of Total Phenolics}

Time is a significant factor influencing the extraction yield of total phenolics. A reasonable extraction time can help shorten the production cycle, reduce energy consumption, and improve yield. However, too long an extraction time will result in the decomposition of the target compounds [29]. To optimize the extraction time, the extraction time was set at 10-60 $\mathrm{min}$, meanwhile, other variables were kept constant (ethanol concentration $70 \%$, extraction temperature $60^{\circ} \mathrm{C}$, and liquid-to-solid ratio $30 \mathrm{~mL} / \mathrm{g}$ ). Figure 1c shows that the extraction yield of total phenolics from CAB increased with time and reached the highest $(92.16 \pm 1.15 \mathrm{mg} \mathrm{GAE} / \mathrm{g} \mathrm{DM})$ when the extraction time was $45 \mathrm{~min}$, and after this point in time, the extraction yield started to decline. Thus, the ultrasonic time was maintained at $45 \mathrm{~min}$ for the next step.

\subsubsection{Effect of Liquid-to-Solid Ratio on Extraction Yield of Total Phenolics}

The liquid-to-solid ratio has a significant role in the mass transfer of extracts between materials and extraction solvents [30]. To obtain the ideal extraction yield of total phenolics, selecting a suitable liquid-to-solid ratio is of the essence. The probable reason is that total phenolics from CAB cannot be fully extracted in the case of low liquid-solid ratio, conversely, when the liquid-solid ratio is too high, the content of impurity and operational cost increases. To optimize the liquid-solid ratio, in this work, the liquid-solid ratio was set at $15-40 \mathrm{~mL} / \mathrm{g}$, meanwhile, other variables were kept constant (ethanol concentration $70 \%$, ultrasonic temperature $60^{\circ} \mathrm{C}$, and extraction time $45 \mathrm{~min}$ ). As shown in Figure $1 \mathrm{~d}$, the extraction yield of total phenolics from $\mathrm{CAB}$ increased from $67.49 \pm 1.12$ to $95.81 \pm 0.79 \mathrm{mg} \mathrm{GAE} / \mathrm{g}$ $\mathrm{DM}$ when the liquid-to-solid ratio increased from 15 to $35 \mathrm{~mL} / \mathrm{g}$. However, on further increasing the liquid-to-solid ratio the extraction yield of total phenolics decreased. Thus, $35 \mathrm{~mL} / \mathrm{g}$ was regarded as the optimal liquid-to-solid ratio.

\subsection{Optimization of Variables by Box-Behnken Design}

\subsubsection{Statistical Analysis and Model Fitting}

Single-factor experiments can only study the effects of changes in one factor on the response variable. The truth, however, is that the influence of variables on response variables is interdependent and mutually restricted. Hence, the influence of the interaction between the main four variables (ethanol concentration, extraction temperature, extraction time, and liquid-to-solid ratio) on extraction yield of total phenolics was researched by the Box-Behnken design. Detailed experimental design and results are summarized in Table 1. 
Table 1. Box-Behnken design matrix and response values for the extraction yield of total phenolics.

\begin{tabular}{|c|c|c|c|c|c|c|}
\hline \multirow{2}{*}{ Run } & \multicolumn{4}{|c|}{ Independent Variables } & \multicolumn{2}{|c|}{ Y (mg GAE/g DM) } \\
\hline & $X_{1}(\%)$ & $\mathrm{X}_{2}\left({ }^{\circ} \mathrm{C}\right)$ & $X_{3}(\min )$ & $\mathrm{X}_{4}(\mathrm{~mL} / \mathrm{g})$ & Experimental & Predicted \\
\hline 1 & 60 & 60 & 45 & 30 & 72.19 & 73.63 \\
\hline 2 & 70 & 60 & 45 & 35 & 95.81 & 94.49 \\
\hline 3 & 70 & 60 & 45 & 35 & 95.37 & 94.49 \\
\hline 4 & 70 & 70 & 45 & 30 & 79.37 & 78.38 \\
\hline 5 & 70 & 50 & 60 & 35 & 74.97 & 76.29 \\
\hline 6 & 80 & 60 & 30 & 35 & 72.36 & 73.48 \\
\hline 7 & 70 & 60 & 30 & 30 & 77.98 & 76.20 \\
\hline 8 & 60 & 60 & 30 & 35 & 68.28 & 70.01 \\
\hline 9 & 80 & 60 & 45 & 30 & 77.99 & 79.74 \\
\hline 10 & 70 & 60 & 30 & 40 & 82.47 & 82.40 \\
\hline 11 & 70 & 50 & 45 & 40 & 72.52 & 73.68 \\
\hline 12 & 60 & 50 & 45 & 35 & 65.69 & 64.30 \\
\hline 13 & 70 & 60 & 45 & 35 & 93.64 & 94.49 \\
\hline 14 & 70 & 60 & 45 & 35 & 93.47 & 94.49 \\
\hline 15 & 70 & 70 & 45 & 40 & 85.27 & 85.21 \\
\hline 16 & 70 & 60 & 60 & 30 & 90.21 & 89.55 \\
\hline 17 & 60 & 60 & 60 & 35 & 81.90 & 80.96 \\
\hline 18 & 80 & 70 & 45 & 35 & 74.01 & 74.67 \\
\hline 19 & 70 & 60 & 45 & 35 & 94.17 & 94.49 \\
\hline 20 & 80 & 50 & 45 & 35 & 69.86 & 68.77 \\
\hline 21 & 80 & 60 & 60 & 35 & 84.4 & 82.84 \\
\hline 22 & 60 & 60 & 45 & 40 & 81.27 & 80.07 \\
\hline 23 & 70 & 60 & 60 & 40 & 88.32 & 89.37 \\
\hline 24 & 70 & 70 & 60 & 35 & 86.22 & 87.01 \\
\hline 25 & 70 & 50 & 30 & 35 & 69.39 & 69.15 \\
\hline 26 & 80 & 60 & 45 & 40 & 80.19 & 79.31 \\
\hline 27 & 70 & 50 & 45 & 30 & 74.26 & 74.50 \\
\hline 28 & 70 & 70 & 30 & 35 & 74.61 & 73.84 \\
\hline 29 & 60 & 70 & 45 & 35 & 73.43 & 73.79 \\
\hline
\end{tabular}

Multiple regression analysis was used to determine the correlation of the four variables and the extraction yield of total phenolics, and a second-order polynomial equation yielded was represented as below:

$$
\begin{aligned}
Y= & -1309.09267+18.69873 X_{1}+13.83737 X_{2}+2.95973 X_{3}+13.61713 X_{4}-0.008975 X_{1} X_{2} \\
& -0.00263333 X_{1} X_{3}-0.0344 X_{1} X_{4}+0.01005 X_{2} X_{3}+0.0382 X_{2} X_{4} \\
& -0.021267 X_{3} X_{4}-0.11931 X_{1}{ }^{2}-0.12178 X_{2}{ }^{2}-0.025506 X_{3}{ }^{2}-0.17491 X_{4}{ }^{2}
\end{aligned}
$$

where $X_{1}, X_{2}, X_{3}$ and $X_{4}$ represent the ethanol concentration, extraction temperature, extraction time, and liquid-to-solid ratio, respectively. $Y$ represents the extraction yield of total phenolics.

The parameters acquired from the analysis of variance (ANOVA) for the Box-Behnken design are listed in Table 2. A model with an F-value of 66.3436 and $p$-value of $<0.0001$ meant that the model was highly significant. It also meant this model was very consistent with experimental data. The $F$-value and $p$-value of the lack of fit were 2.6222 and 0.1829 , respectively, which meant that the lack of fit was not significant relative to the pure error. The coefficient $\left(R^{2}=0.9852\right)$ meant this model could account for $98.52 \%$ of the response value changes and the fitting precision of this model was satisfactory. The adjusted coefficient (Adj. $R^{2}=0.9703$ ) was close to the $R^{2}$, which meant that the experimental values fitted well with the predicted values. The value of the coefficient of variation (C.V\%) was very low (1.91), which meant the model was repeatable [31]. In addition, the linear coefficients $\left(X_{1}, X_{2}, X_{3}\right.$, and $\left.X_{4}\right)$, cross product coefficients $\left(X_{1} X_{4}\right.$ and $\left.X_{2} X_{4}\right)$, and quadratic coefficient $\left(X_{1}{ }^{2}, X_{2}{ }^{2}, X_{3}{ }^{2}\right.$, and $\left.X_{4}{ }^{2}\right)$ were significant $(p<0.05)$. 
Table 2. ANOVA for Box-Behnken design.

\begin{tabular}{cccccc}
\hline Source & Sum of Squares & df & Mean Square & F-Value & $p$-Value \\
\hline Model & 2196.5259 & 14 & 156.8947 & 66.3436 & $<0.0001^{* * *}$ \\
$\mathrm{X}_{1}$ & 21.4669 & 1 & 21.4669 & 9.0774 & $0.0093^{* *}$ \\
$\mathrm{X}_{2}$ & 178.0240 & 1 & 178.0240 & 75.2782 & $<0.0001^{* * *}$ \\
$\mathrm{X}_{3}$ & 309.3721 & 1 & 309.3721 & 130.8193 & $<0.0001^{* * *}$ \\
$\mathrm{X}_{4}$ & 27.1201 & 1 & 27.1201 & 11.4679 & $0.0044^{* *}$ \\
$\mathrm{X}_{1} \mathrm{X}_{2}$ & 3.2220 & 1 & 3.2220 & 1.3624 & $0.2626^{*}$ \\
$\mathrm{X}_{1} \mathrm{X}_{3}$ & 0.6241 & 1 & 0.6241 & 0.2639 & 0.6154 \\
$\mathrm{X}_{1} \mathrm{X}_{4}$ & 11.8336 & 1 & 11.8336 & 5.0039 & $0.0421^{* *}$ \\
$\mathrm{X}_{2} \mathrm{X}_{3}$ & 9.0902 & 1 & 9.0902 & 3.8438 & $0.0701^{*}$ \\
$\mathrm{X}_{2} \mathrm{X}_{4}$ & 14.5924 & 1 & 14.5924 & 6.1705 & $0.0263^{*}$ \\
$\mathrm{X}_{3} \mathrm{X}_{4}$ & 10.1761 & 1 & 10.1761 & 4.3030 & 0.0570 \\
$\mathrm{X}_{1}^{2}$ & 923.4078 & 1 & 923.4078 & 390.4671 & $<0.0001^{* * *}$ \\
$\mathrm{X}_{2}{ }^{2}$ & 961.9172 & 1 & 961.9172 & 406.7509 & $<0.0001^{* * *}$ \\
$\mathrm{X}_{3}{ }^{2}$ & 213.6335 & 1 & 213.6335 & 90.3359 & $<0.0001^{* * *}$ \\
$\mathrm{X}_{4}{ }^{*}$ & 124.0230 & 1 & 124.0230 & 52.4437 & $<0.0001^{* * *}$ \\
Residual & 33.1083 & 14 & 2.3649 & & 0.1829 \\
Lack of Fit & 28.7262 & 10 & 2.8726 & 2.6222 & \\
Pure Error & 4.3821 & 4 & 1.0955 & & \\
Cor Total & 2229.6342 & 28 & & &
\end{tabular}

\subsubsection{Optimization of UAE Procedure}

In order to provide a better visual representation of the effects of interactions between the independent variables on the response value, three-dimensional response surface plots drawn by the Box-Behnken Design were shown in Figure 2a-f. For each figure, the extraction yield of total phenolics was gained by changing two variables while the other two variables remained unchanged [32]. Figure 2a-f shows the effects of the pairwise interaction between the ethanol concentration and extraction temperature on the extraction yield of total phenolics. It can be seen that the extraction yield of total phenolics increased rapidly with increasing ethanol concentration from $60 \%$ to about $70 \%$, and followed by a decrease thereafter, meanwhile, the extraction yield of total phenolics increased rapidly when the extraction temperature changed from $50{ }^{\circ} \mathrm{C}$ to $62{ }^{\circ} \mathrm{C}$, and decreased afterwards. Similarly, the extraction yield of total phenolics increased greatly with the increase of extraction time from $30 \mathrm{~min}$ to about $52 \mathrm{~min}$, whereas it decreased over $52 \mathrm{~min}$. The liquid-to-solid ratio exhibited a weaker effect on the extraction yield of total phenolics, and the extraction yield of total phenolics increased slowly with the increase of liquid-to-solid ratio from $30 \mathrm{~mL} / \mathrm{g}$ to $36 \mathrm{~mL} / \mathrm{g}$, and then declined.

\subsubsection{Verification of Predictive Model}

The optimal extraction conditions $\left(\mathrm{X}_{1} 70.31 \%, \mathrm{X}_{2} 61.94{ }^{\circ} \mathrm{C}, \mathrm{X}_{3} 51.73 \mathrm{~min}\right.$, and $\left.\mathrm{X}_{4} 35.63 \mathrm{~mL} / \mathrm{g}\right)$ were obtained from Figure 2. Under the optimal conditions, a maximum response value $(\mathrm{Y})$ of $96.12 \mathrm{mg}$ GAE/g DM was obtained from the mathematical prediction of the model. Subsequently, to verify the accuracy and practicability of the model equation, verification experiments were performed. The extraction yield of total phenolics from CAB was $95.84 \mathrm{mg}$ GAE/g DM. This fact proved that the model equation was perfectly suitable for the optimization of the UAE process. 


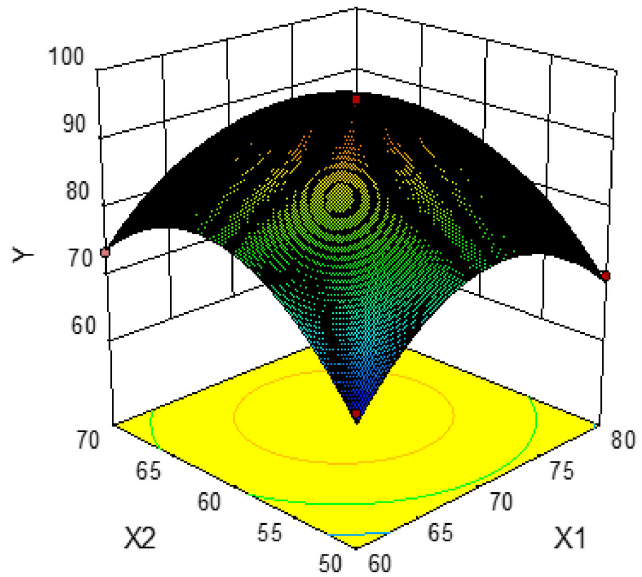

(a)

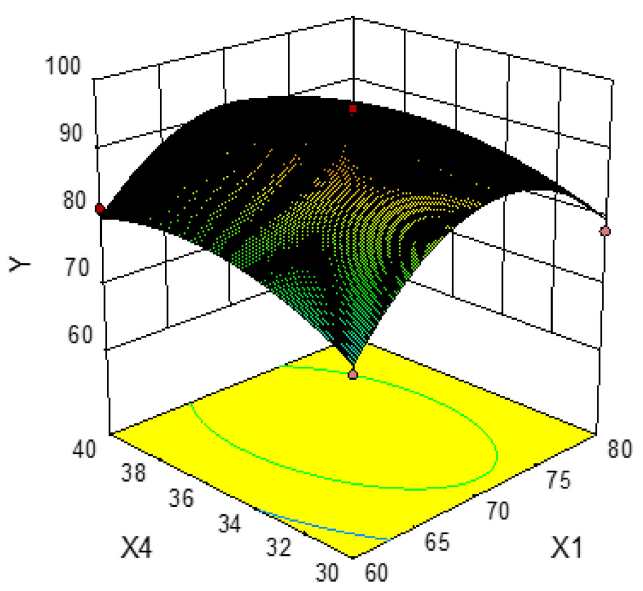

(c)

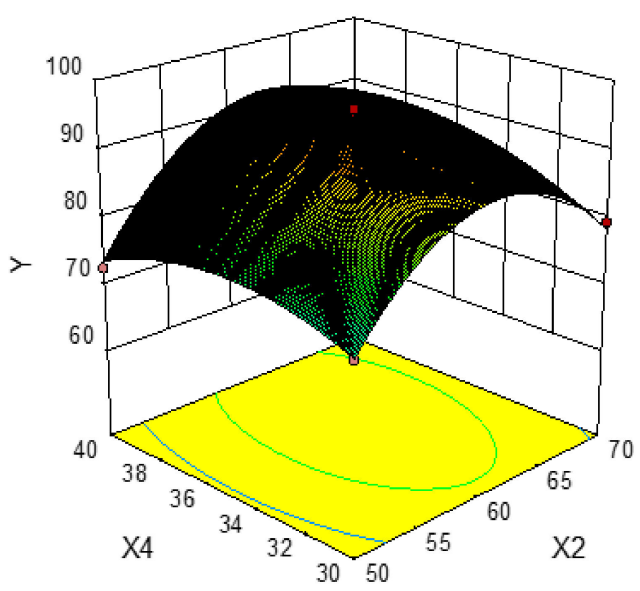

(e)

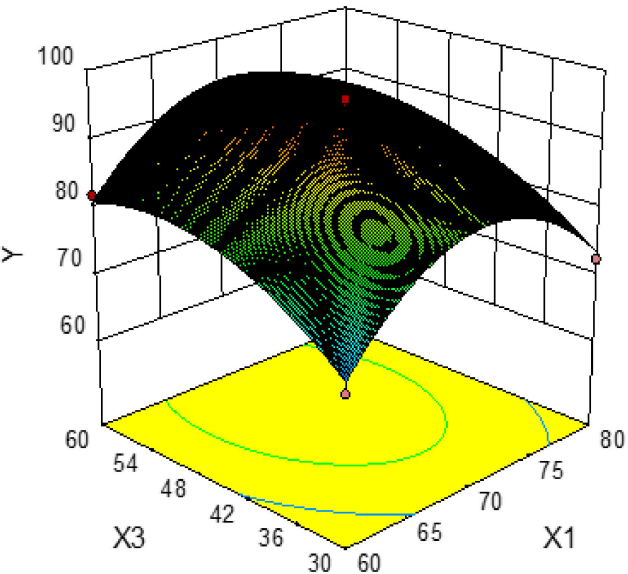

(b)

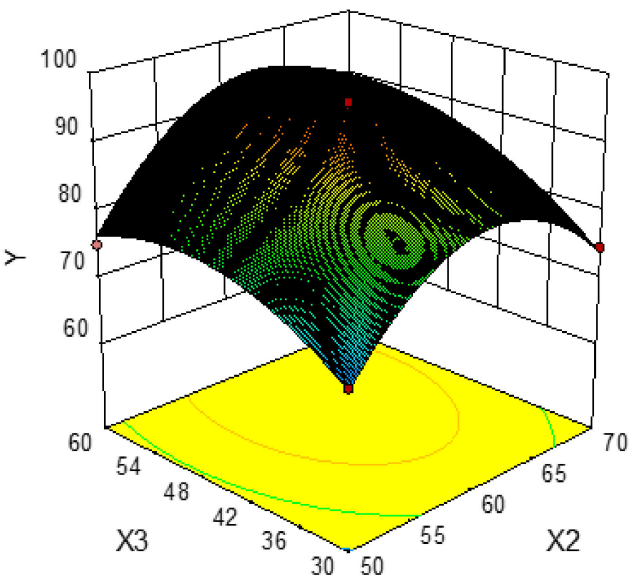

(d)

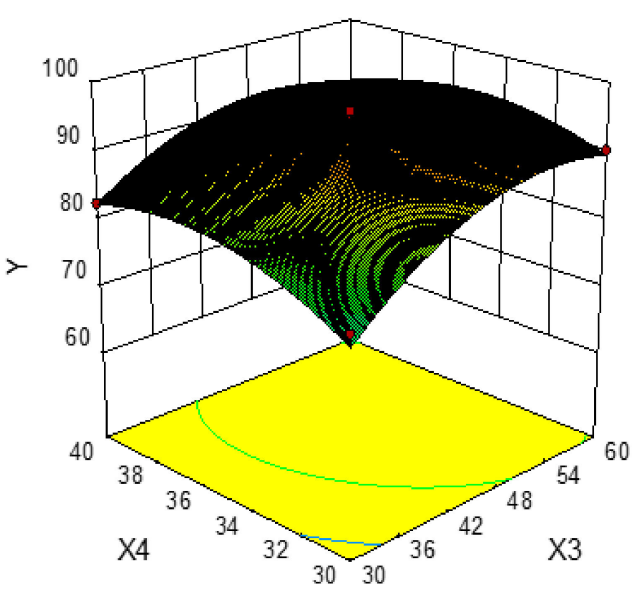

(f)

Figure 2. Response surface plots showing the effects of variables on the extraction yield of total phenolics: interaction of the ethanol concentration and extraction temperature (a), interaction of ethanol concentration and extraction time (b), interaction of ethanol concentration and liquid-to-solid ratio (c), interaction of extraction temperature and extraction time $(\mathbf{d})$, interaction of extraction temperature and liquid-to-solid ratio (e), interaction of extraction time and liquid-to-solid ratio (f). 


\subsection{Comparison of $U A E$ and HRE}

In addition, to evaluate the efficiency of UAE, conventional HRE of total phenolics from CAB was also performed. Compared with UAE, the HRE method had a lower extraction yield of total phenolics (78.32 $\pm 1.83 \mathrm{mg}$ GAE/g DM). UAE could significantly improve the extraction yield of total phenolics, which could be attributed to the fact that the cavitation effects, thermal effects, and mechanical effects have positive influences on the extraction process [33]. Additionally, compared to previous reports, the extraction yield of total phenolics obtained by UAE in this work was much higher than those obtained by conventional hot water, ethanol, methanol extraction [16].

\subsection{Analysis of Phenolic Compounds by HPLC}

A comparative study on the effects of UAE and conventional HRE on the contents of individual phenolic compounds in $\mathrm{CAB}$ was conducted. As shown in Figure 3, the five main phenolic compounds detected were hesperetin, hesperidin, naringin, neohesperidin, and eriocitrin, which was in general agreement with previous research [15]. The contents of individual phenolic compounds detected are listed in Table 3, and it was observed that the content of each component extracted by UAE was higher than that obtained by HRE. Naringin contents of $6.17 \pm 0.04$ and $5.03 \pm 0.03 \mathrm{mg} / \mathrm{g}$, hesperidin contents of $10.22 \pm 0.06$ and $8.25 \pm 0.02 \mathrm{mg} / \mathrm{g}$, and neohesperidin contents of $15.45 \pm 0.05$ and $11.77 \pm 0.03 \mathrm{mg} / \mathrm{g}$ were quantified respectively, which were very consistent with the result reported by Shen et al. that naringin, hesperidin and neohesperidin are the predominant phenolic compounds in CAB [17]. To our knowledge this was the first study that reported the contents of eriocitrin $(1.62 \pm 0.03 \mathrm{mg} / \mathrm{g})$ and hesperetin $(0.68 \pm 0.03 \mathrm{mg} / \mathrm{g})$ in CAB. In addition, Karimi et al. reported the content of quercetin as $0.185 \mathrm{mg} / \mathrm{g}$ [16], but we did not actually detect this compound. One possible explanation for this was that the levels of phytochemicals depend on many factors including cultivar variation, environmental condition, and harvest time [34].

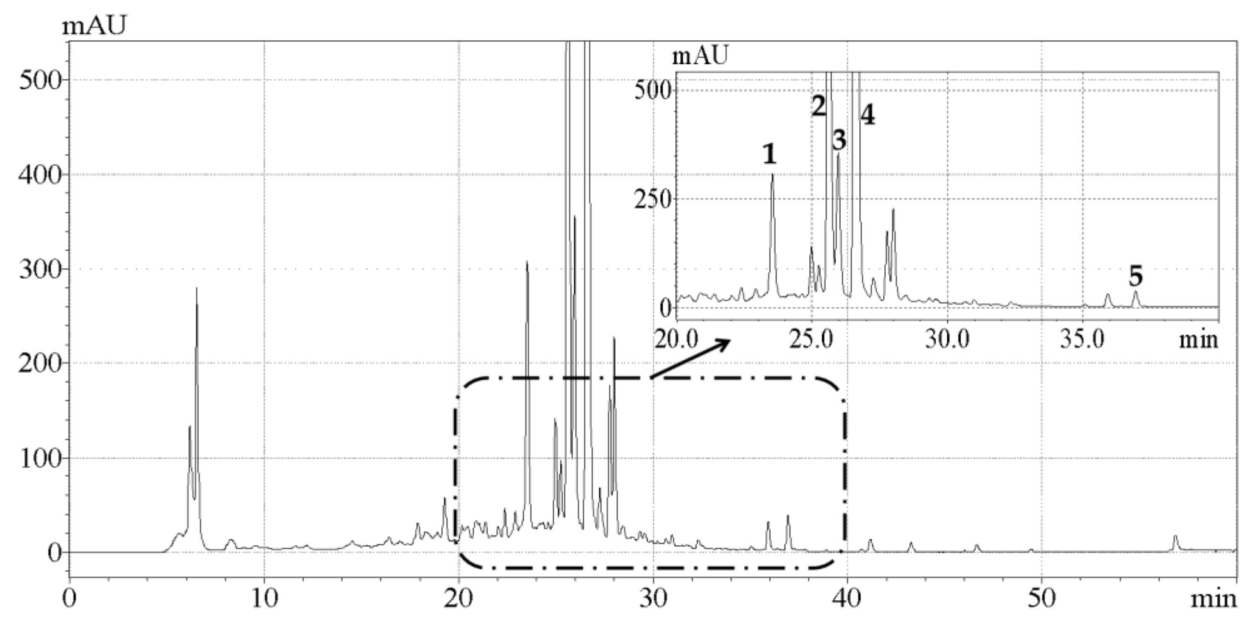

Figure 3. HPLC-DAD chromatogram of the extracts obtained by ultrasonic-assisted extraction under optimized conditions. Peaks 1, 2, 3, 4, and 5 represent eriocitrin, naringin, hesperidin, neohesperidin, and hesperetin, respectively.

Table 3. Comparison of individual phenolic compounds contents in CAB extracted by UAE and HRE.

\begin{tabular}{cccccc}
\hline \multirow{2}{*}{$\begin{array}{c}\text { Extraction } \\
\text { Method }\end{array}$} & \multicolumn{5}{c}{ Content of Individual Phenolic Compounds (mg/g) } \\
\cline { 2 - 6 } & Eriocitrin & Naringin & Hesperidin & Neohesperidin & Hesperetin \\
\hline UAE & $1.62 \pm 0.03$ & $6.17 \pm 0.04$ & $10.22 \pm 0.03$ & $15.45 \pm 0.05$ & $0.68 \pm 0.03$ \\
HRE & $1.17 \pm 0.02$ & $5.03 \pm 0.03$ & $8.25 \pm 0.02$ & $11.77 \pm 0.03$ & $0.56 \pm 0.01$ \\
\hline
\end{tabular}




\subsection{Evaluation of Free Radical Scavenging Activities}

\subsubsection{DPPH. Scavenging Activity}

Scavenging of DPPH. is a common model used to study the free radical scavenging activity of natural extracts. The DPPH. scavenging activity of a substance is quantitatively related to the number of electrons received by DPPH. Figure 4a showed that the DPPH. scavenging activity of total phenolic extract from $\mathrm{CAB}$ increased in a concentration-dependent manner at concentrations ranging from 50 to $300 \mu \mathrm{g} / \mathrm{mL}$, throughout slightly lower than trolox. At a concentration of $300 \mu \mathrm{g} / \mathrm{mL}$, the DPPH. scavenging activity of total phenolic extracts from $\mathrm{CAB}$ and trolox were $80.54 \% \pm 1.94 \%$ and $91.32 \% \pm 2.21 \%$, respectively. Besides, the $\mathrm{IC}_{50}$ values of total phenolic extracts from $\mathrm{CAB}$ and trolox were 197.007 and $157.469 \mu \mathrm{g} / \mathrm{mL}$, respectively. Also, the total phenolic extracts from $\mathrm{CAB}$ under the optimal conditions showed a higher DPPH. scavenging activity than methanolic, ethanolic, and aqueous extracts [16].

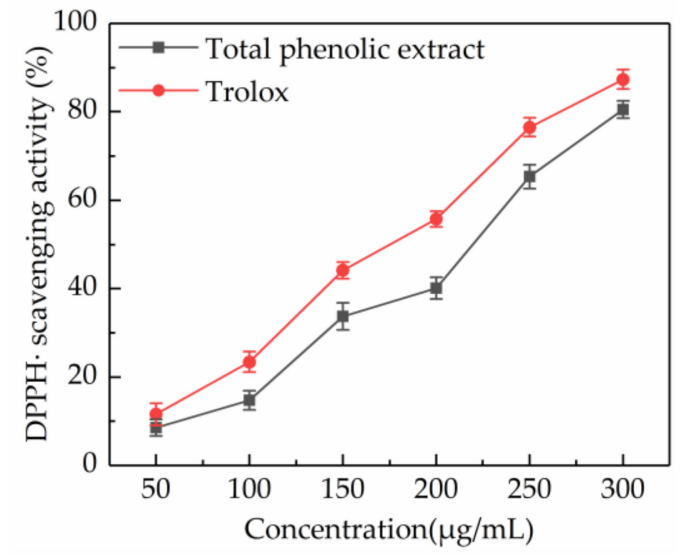

(a)

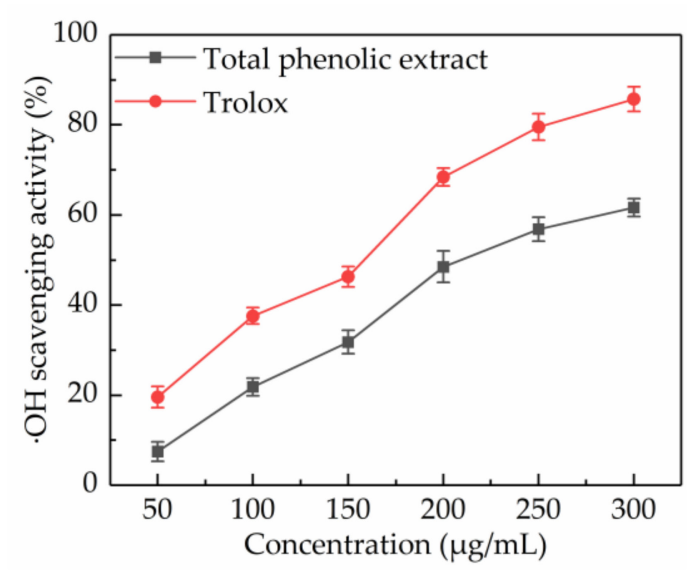

(c)

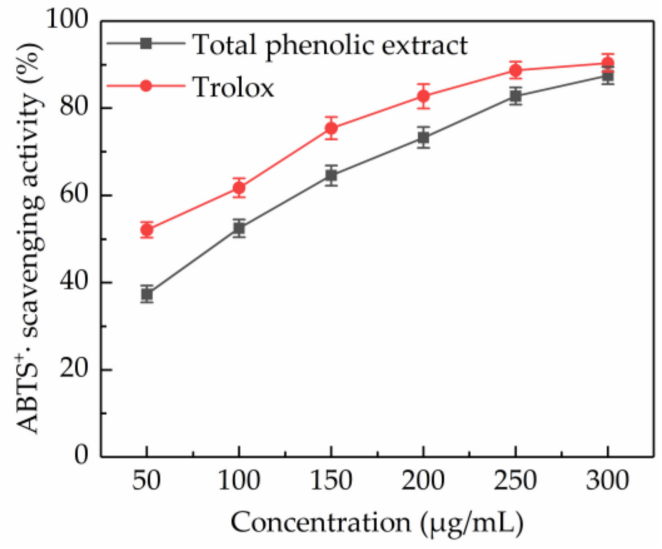

(b)

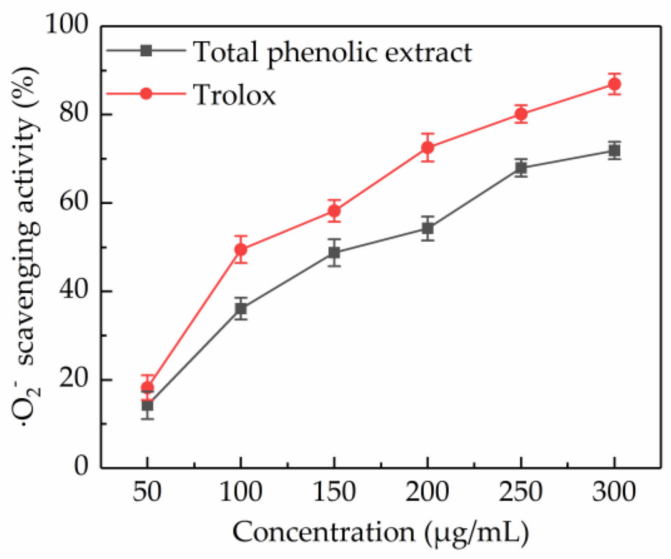

(d)

Figure 4. Free radical scavenging activities of total phenolic extract at concentrations of 50, 100, 150, 200, 250, and $300 \mu \mathrm{g} / \mathrm{mL}$. DPPH. scavenging activity (a), $\mathrm{ABTS}^{+}$. scavenging activity (b), $\cdot \mathrm{OH}$ scavenging activity (c) and $\cdot \mathrm{O}_{2}{ }^{-}$scavenging activity $(\mathbf{d})$.

\subsection{2. $\mathrm{ABTS}^{+}$. Scavenging Activity}

$\mathrm{ABTS}^{+}$. scavenging activity assay is another important measure to evaluate the free radical scavenging activity of natural products. ABTS can be oxidized into green $\mathrm{ABTS}^{+}$. under the action of oxidants, and the production of $\mathrm{ABTS}^{+}$. is inhibited in the presence of antioxidants. $\mathrm{ABTS}^{+}$. scavenging activities of total phenolic extract from $\mathrm{CAB}$ and trolox are displayed in Figure $4 \mathrm{~b}$. It was found that 
their $\mathrm{ABTS}^{+}$. scavenging activities increased with increasing concentration. When the concentration was in the range of $50-300 \mu \mathrm{g} / \mathrm{mL}$, the $\mathrm{ABTS}^{+}$. scavenging activity of total phenolic extract from $\mathrm{CAB}$ was slightly weaker than trolox. Additionally, the $\mathrm{IC}_{50}$ values were 83.878 and $53.746 \mu \mathrm{g} / \mathrm{mL}$, respectively, for total phenolic extract from $C A B$ and trolox. Hence, the total phenolic extract from $\mathrm{CAB}$ was considered to have a high $\mathrm{ABTS}^{+}$. scavenging activity.

\subsubsection{OH Scavenging Activity}

The $\cdot \mathrm{OH}$ radical has very strong oxidation ability due to its extremely effective ability to acquire electrons, which can be generated through the Fenton reaction. Almost all biological molecules are exposed to oxidative damage because of surplus $\cdot \mathrm{OH}$. Figure $4 \mathrm{c}$ shows that the $\cdot \mathrm{OH}$ scavenging activity of total phenolic extract from CAB increased with an increase in concentration. A $300 \mu \mathrm{g} / \mathrm{mL}$ of total phenolic extract from $\mathrm{CAB}$ and trolox exhibited $61.65 \% \pm 1.97 \%$ and $85.74 \% \pm 2.72 \%$ scavenging activity respectively, and their $\mathrm{IC}_{50}$ values were 218.643 and $129.665 \mathrm{mg} / \mathrm{mL}$, respectively. Those results indicated that the total phenolic extracts from $\mathrm{CAB}$ were good scavengers of $\cdot \mathrm{OH}$.

\subsection{4. $\cdot \mathrm{O}_{2}{ }^{-}$Scavenging Activity}

Although $\cdot \mathrm{O}_{2}{ }^{-}$is a weak oxidant, it can cause damage to an organism, because it is ubiquitous and can degrade to other kinds of reactive oxygen species. Hence, scavenging $\cdot \mathrm{O}_{2}{ }^{-}$is also very necessary. As shown in Figure $4 \mathrm{~d}$, trolox exhibited a better $\cdot \mathrm{O}_{2}{ }^{-}$scavenging activity than the total phenolic extracts from $\mathrm{CAB}$ at concentrations from 50 to $300 \mu \mathrm{g} / \mathrm{mL}$, and their $\cdot \mathrm{O}_{2}{ }^{-}$scavenging activities were dose-dependent. At a concentration of $300 \mu \mathrm{g} / \mathrm{mL}$, total phenolic extract from CAB and trolox respectively exhibited $74.84 \% \pm 1.96 \%$ and $86.94 \% \pm 2.37 \%$. Besides, the $\mathrm{IC}_{50}$ of total phenolic extract from $\mathrm{CAB}$ was $158.885 \mu \mathrm{g} / \mathrm{mL}$, whereas the $\mathrm{IC}_{50}$ of trolox was $112.520 \mu \mathrm{g} / \mathrm{mL}$. These results proved that the total phenolic extract from $\mathrm{CAB}$ can scavenge $\cdot \mathrm{O}_{2}{ }^{-}$effectively.

\subsection{Evaluation of Anti-HMG-CoA Reductase Activity}

The in vitro test of anti-HMG-CoA reductase activity of the total phenolic extract was carried out and the result is shown in Figure 5. It was demonstrated that the total phenolic extract significantly inhibited HMG-CoA reductase activity when the concentration was higher than $160 \mu \mathrm{g} / \mathrm{mL}$; the inhibition drastically increased from $2.35 \%$ to $64.27 \%$ when the concentration of total phenolic extracts was within the range $5-320 \mu \mathrm{g} / \mathrm{mL}$, and the $\mathrm{IC}_{50}$ value was $117.165 \mu \mathrm{g} / \mathrm{mL}$. Besides, the $\mathrm{IC}_{50}$ value measured for pravastatin was $68.54 \mathrm{nM}$, which was consistent with a previous report [35]. These results suggested that the total phenolic extract from $C A B$ might help in reducing the production of cholesterol.

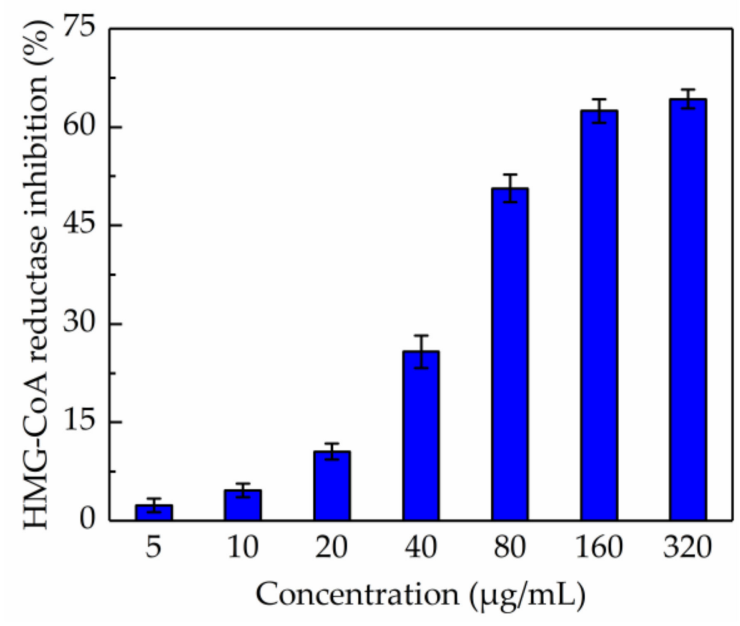

Figure 5. Inhibition of $\beta$-hydroxy- $\beta$-methylglutaryl-CoA reductase activity by total phenolic extract. 


\section{Materials and Methods}

\subsection{Chemicals and Reagents}

Folin-Ciocalteu, trolox, gallic acid, 1,1-diphenyl-2-picrylhydrazyl (DPPH), 2,2'-azino-bis (3-ethyl-benzothiazoline-6-sulfonic acid) diammonium salt (ABTS), nitroblue tetrazolium (NBT) chloride, $N$-methylphenazonium methyl sulfate (PMS), nicotinamide adenine dinucleotide (NADH) were purchased from Sigma Chemical Co. (St. Louis, MO, USA). Other analytical grades of methanol, ethanol, $\mathrm{H}_{2} \mathrm{O}_{2}, \mathrm{FeSO}_{4}, \mathrm{~K}_{2} \mathrm{~S}_{2} \mathrm{O}_{8}$ and salicylic acid were purchased from Tianjin Kemio Chemical Co. (Tianjin, China).

\subsection{Plant Material}

CAB were collected in March 2018, from Jinhua city, Zhejiang province, China. A voucher specimen (DDY-20180301) was deposited at the Key Laboratory of Biotechnology and Bioresources Utilization, Ministry of Education, Dalian, China. The raw material was dried, powdered, and sifted with an 80-mesh sieve, before finally preserving in a desiccator.

\subsection{UAE of Total Phenolics}

\subsubsection{Single-Factor Experiments}

UAE of total phenolics from CAB was carried out with an ultrasonic apparatus (KQ-5200DE, Kunshan ultrasonic Co. Ltd., Suzhou, China), and ultrasound frequency and ultrasound power were set as $40 \mathrm{kHz}$ and $100 \mathrm{~W}$, respectively [36,37]. Each $5 \mathrm{~g}$ of sample powder was placed into a volumetric flask $(250 \mathrm{~mL})$, then extracted with various ethanol concentrations (30\%, 40\% 50\%, 60\%, 70\%, 80\%), temperatures $\left(30,40,50,60,70,80^{\circ} \mathrm{C}\right)$, liquid-solid ratio $(15,20,25,30,35,40 \mathrm{~mL} / \mathrm{g})$ for various times $(15,30,45,60,75,90 \mathrm{~min})$ respectively. The extracts were filtered, combined, after which the extraction solvent was replenished to bring the final volume of the extract to $250 \mathrm{~mL}$. The extraction yield of total phenolics from $\mathrm{CAB}$ for each extraction experiment was expressed as $\mathrm{mg}$ of gallic acid equivalent (GAE) on g of dry matter (DM).

\subsubsection{Box-Behnken Design}

The Box-Behnken is an efficient design for response surface methodology, which has been widely applied to optimize the extraction process of natural active substances. In this work, based on single-factor experiments, a Box-Behnken design with four factors (ethanol concentration $X_{1}$, extraction temperature $X_{2}$, extraction time $X_{3}$, and liquid-solid ratio $\left.X 4\right)$ and three levels $(-1,0,+1)$ including 29 experimental runs, was used to evaluate the combined effects on the extraction yield of total phenolics. A second-order polynomial model was used to describe the mathematical relationship between independent variables and response values.

$$
Y=\alpha_{0}+\sum_{i=1}^{4} \alpha_{i} X_{i}+\sum_{i=1}^{4} \alpha_{i i} X_{i}^{2}+\sum_{i=1}^{3} \sum_{j=i+1}^{4} \alpha_{i j} X_{i} X_{j}
$$

where $Y$ is the response variable, $X_{i}$ and $X_{j}$ are independent variables, $\alpha_{0}$ is a constant coefficient, $\alpha_{1}, \alpha_{2}$, and $\alpha_{3}$ represent the linear coefficient, interaction coefficient of two variables and quadratic coefficient of one variable, respectively.

\subsection{HRE of Total Phenolics from $C A B$}

HRE of total phenolics from CAB was performed under the optimal UAE conditions with slightly modification. Briefly, $5 \mathrm{~g}$ of sample powder was kept in a thermostatic water bath at $62{ }^{\circ} \mathrm{C}$ and extracted three times with $175 \mathrm{~mL}$ of $70 \%$ ethanol under reflux, each time for $52 \mathrm{~min}$. After HRE, the extracts were processed by the method described in Section 3.3.1. 


\subsection{Determination of Total Phenolic Content}

The measurement of total phenolics content was conducted using the Folin-Ciocalteu colorimetric method as described by Seifzadeh et al. [38]. Briefly, $0.25 \mathrm{~mL}$ of total phenolic extract solution was blended with $1.25 \mathrm{~mL}$ of the Folin-Ciocalteu reagent (diluted 10-fold by deionized water), then the mixture was neutralized by the addition of $1 \mathrm{~mL}$ of $7.5 \% \mathrm{Na}_{2} \mathrm{CO}_{3}$. After one hour of incubation at $45^{\circ} \mathrm{C}$ in the dark, the absorbance was recorded at $765 \mathrm{~nm}$. Gallic acid was used as a standard. The total phenolics content in the extracts was calculated using the linear regression equation:

$$
A=0.1265 C+0.0228\left(n=6, R^{2}=0.9997\right)
$$

where $A$ was the absorbance of the sample, $C$ the final total phenolics concentration.

\subsection{HPLC Analysis}

The extracts obtained from UAE under optimized conditions and conventional HRE were analyzed by an HPLC system (Shimadzu, Kyoto, Japan), which was equipped with two LC-20AD pumps and a diode array detector (SPD-M20A). All chromatography experiments were performed on a YMC-Pack ODS-A C18 $(250 \mathrm{~mm} \times 4.6 \mathrm{~mm}, 5 \mu \mathrm{m})$. The mobile phase was comprised of solvent A $(0.1 \%$ TFA in water $)$ and solvent B (acetonitrile). The solvent gradient in volume ratios was as follows: $0-60 \mathrm{~min}, 10-100 \% \mathrm{~B}$. The system was operated at a flow rate of $0.5 \mathrm{~mL} / \mathrm{min}$. Analyses were carried out at room temperature, the detection wavelength was set at $280 \mathrm{~nm}$. The phenolic compounds including hesperetin, hesperidin, naringin, neohesperidin, and eriocitrin were identified by comparison with the retention time and UV spectra of individual standards, and quantified using the external standard method.

\subsection{Free Radical Scavenging Activity Assay}

\subsubsection{DPPH· Scavenging Activity}

The DPPH- scavenging activity assay was operated as the procedure described by Shen et al. [39] with slight modifications. Briefly, $3.2 \mathrm{~mL}$ of freshly prepared DPPH solution $(0.2 \mathrm{mM}$ in ethanol $)$ and $0.4 \mathrm{~mL}$ of phenolic extracts in ethanol at different concentrations $(50-300 \mu \mathrm{g} / \mathrm{mL})$ were mixed and shaken well in the dark at room temperature. After $60 \mathrm{~min}$, the absorbance was measured at $517 \mathrm{~nm}$ using a spectrophotometer (UV-2600, Shimadzu, Japan). The DPPH. scavenging activity of trolox was also analyzed for positive control. The percentage of DPPH. scavenging was calculated by the following equation:

$$
\mathrm{DPPH} \cdot \text { scavenging activity }(\%)=\left(1-\frac{A_{\text {sample }}}{A_{\text {blank }}}\right) \times 100
$$

where $A_{\text {sample }}$ was the absorbance of the total phenolic extract, and the $A_{\text {balnk }}$ was the absorbance of the sample without phenolic extract.

\subsection{2. $\mathrm{ABTS}^{+}$. Scavenging Activity Assay}

The $\mathrm{ABTS}^{+}$. scavenging activity assay was conducted as in the method described by a previous study with slight modifications [40]. Briefly, a redox reaction was triggered by blending the ABTS solution $(7.0 \mathrm{mM})$ and $\mathrm{K}_{2} \mathrm{~S}_{2} \mathrm{O}_{8}$ solution $(2.45 \mathrm{mM})$ in a ratio of $1: 1$. After $16 \mathrm{~h}$, the reaction solution was adjusted with ethanol to yield an absorbance between 0.68 and 0.72 at $734 \mathrm{~nm}$. Then, $125 \mu \mathrm{L}$ of each sample (50, 100, 150, 200, 250 and $300 \mu \mathrm{g} / \mathrm{mL}$ ) was mixed with $200 \mu \mathrm{L}$ of $\mathrm{ABTS}^{+}$. solution. After one minute, the absorbance was recorded at $734 \mathrm{~nm}$. Trolox was used as a standard. The percentage of $\mathrm{ABTS}^{+}$. scavenging was calculated using the following equation:

$$
\mathrm{ABTS}^{+} \cdot \text { scavenging activity }(\%)=\left(1-\frac{A_{\text {sample }}}{A_{\text {blank }}}\right) \times 100
$$


where $A_{\text {sample }}$ was the absorbance of the total phenolic extract, and the $A_{\text {balnk }}$ was the absorbance of a blank (without total phenolic extract).

\subsection{3. $\cdot \mathrm{OH}$ Scavenging Activity Assay}

The $\cdot \mathrm{OH}$ scavenging activity of total phenolic extract was measured according to the method reported previously with some modifications [41]. The $\cdot \mathrm{OH}$ was obtained through a Fenton reaction. Explicitly, the reaction system consisted of $1.0 \mathrm{~mL} \mathrm{FeSO}_{4}(9.0 \mathrm{mM}), 1.0 \mathrm{~mL} \mathrm{H}_{2} \mathrm{O}_{2}(9.0 \mathrm{mM})$, and $1.0 \mathrm{~mL}$ of total phenolic extract at different concentrations $(50,100,150,200,250$, and $300 \mathrm{mg} / \mathrm{mL}$ ), then $1.0 \mathrm{~mL}$ of salicylic acid $(3.0 \mathrm{mM})$ was added to initiate the reaction. The reaction mixture was incubated at $37^{\circ} \mathrm{C}$ for one hour, and the absorbance was measured at $510 \mathrm{~nm}$. Trolox was used as a positive control. The $\cdot \mathrm{OH}$ scavenging activity was measured using the following equation:

$$
\text { . OH scavenging activity }(\%)=\left(1-\frac{A_{1}-A_{2}}{A_{0}}\right) \times 100
$$

where, $A_{0}, A_{1}$, and $A_{2}$ are the absorbance of the blank control (without total phenolic extract), the absorbance of total phenolic extract and the absorbance without $\mathrm{H}_{2} \mathrm{O}_{2}$, respectively.

\subsection{4. $\cdot \mathrm{O}_{2}-$ Scavenging Activity Assay}

The $\cdot \mathrm{O}_{2}{ }^{-}$scavenging activity of total phenolic extract was measured based on the modified method described previously [42]. Briefly, the reaction system consisted of $3 \mathrm{~mL}$ of Tris- $\mathrm{HCl}$ buffer solution $(16 \mathrm{mM}, \mathrm{pH} 8.0)$ containing $1 \mathrm{~mL}$ of NBT $(50 \mu \mathrm{M}), 1 \mathrm{~mL}$ of NADH $(78 \mu \mathrm{M})$, and $1 \mathrm{~mL}$ of total phenolic extract at different concentrations $(50,100,150,200,250$ and $300 \mu \mathrm{g} / \mathrm{mL})$. Then $1.0 \mathrm{~mL}$ of PMS $(10 \mu \mathrm{M})$ was added into the system to initiate the reaction. The mixture was maintained at $25^{\circ} \mathrm{C}$ for five minutes, followed by measurement of the absorbance at $560 \mathrm{~nm}$. Trolox was used as a comparison. The $\cdot \mathrm{O}_{2}{ }^{-}$scavenging activity was measured using the following equation:

$$
\text { . } \mathrm{O}_{2}{ }^{-} \text {scavenging activity }(\%)=\left(1-\frac{A_{\mathrm{b}}}{A_{\mathrm{s}}}\right) \times 100
$$

where $A_{\mathrm{s}}$ and $A_{\mathrm{b}}$ are the absorbance of the total phenolic extract and the absorbance of the blank control (without total phenolic extract), respectively.

\subsection{Anti-HMG-CoA Reductase Activity Assay}

HMG-CoA reductase inhibitory activity of the total phenolic extract from CAB was evaluated with the commercially available HMG-CoA reductase assay kit purchased from Sigma-Aldrich (St. Louis, MO, USA) [43,44]. The specific operation method was in accordance with the instruction: each well of 96-well plate containing $1 \mu \mathrm{L}$ of different concentrations of total phenolic extract, $4 \mu \mathrm{L}$ of NADPH (final concentration of $400 \mu \mathrm{M}$ ), $12 \mu \mathrm{L}$ of HMG-CoA substrate (final concentration of $300 \mu \mathrm{g} / \mathrm{mL}$ ), followed by the addition of phosphate buffer ( $\mathrm{pH} 7.4$ ) to achieve a final volume of $200 \mu \mathrm{L}$. Then, $2 \mu \mathrm{L}$ of the HMG-CoA reductase was added into each well to activate the reaction system. Immediately, the 96-well plate was shaken mechanically in a microplate reader (BioTek, Synergy H1, Winooski, VT, USA) for $10 \mathrm{~s}$. The consumption rate of NADPH was measured once at $20 \mathrm{~s}$ for up to $600 \mathrm{~s}$ by recording the absorbance of the reaction system at $340 \mathrm{~nm}$. Pravastatin was used as positive control. The HMG-CoA reductase inhibition (\%) was calculated using the following formula:

$$
\text { HMG - CoA reductase inhibition }(\%)=\frac{\Delta A_{\text {control }}-\Delta A_{\text {test }}}{\Delta A_{\text {control }}} \times 100
$$

where $A_{\text {test }}$ and $A_{\text {control }}$ are the absorbance of the total phenolic extract and the absorbance of control (without total phenolic extract), respectively 


\subsection{Statistical Methods}

The data were reported as the mean \pm standard deviation (SD) from three parallel experiments. The half maximal inhibitory concentration $\left(\mathrm{IC}_{50}\right)$ was calculated using the linear regression method by the SPSS 24.0 software (SPSS Inc., Chicago, IL, USA). Design-Expert 10 (Stat-Ease Inc., Minneapolis, MN, USA) was used for designing the experiments and statistical analysis.

\section{Conclusions}

In the present work, the optimum UAE technology to obtain total phenolics from $\mathrm{CAB}$ was successfully developed through single-factor experiments coupled with the Box-Behnken design. The optimum parameters including ethanol concentration, ultrasonic temperature, ultrasonic time, liquid-to-solid ratio were $70.31 \%, 61.94{ }^{\circ} \mathrm{C}, 51.73 \mathrm{~min}$ and $35.63 \mathrm{~mL} / \mathrm{g}$, respectively. Under these conditions, the extraction yield of total phenolics from $\mathrm{CAB}$ was $95.84 \mathrm{mg} \mathrm{GAE} / \mathrm{g} \mathrm{DM}$, which was close to the theoretical value (96.12 mg GAE/g DM). Based on the HPLC analysis, UAE under optimized conditions was a more efficient method for extracting phenolic compounds including eriocitrinnaringin, hesperidin, neohesperidin, and hesperetin compared with conventional HRE. In addition, the study on free radical scavenging activities indicated that the total phenolic extract obtained under the optimum condition had excellent scavenging effects on $\mathrm{DPPH} \cdot, \mathrm{ABTS}^{+} \cdot, \cdot \mathrm{OH}$, and $\cdot \mathrm{O}_{2}{ }^{-}$, with the corresponding $\mathrm{IC}_{50}$ values of $197.007,83.878,218.643$, and $158.885 \mu \mathrm{g} / \mathrm{mL}$, while the total phenolic extract also exhibited good potential to inhibit HMG-CoA reductase in vitro, with an $\mathrm{IC}_{50}$ value of $117.165 \mu \mathrm{g} / \mathrm{mL}$. Therefore, the study is conducive for the optimum utilization of $\mathrm{CAB}$ as a great source of total phenolics with good free radical scavenging, anti-HMG-CoA reductase activities.

Author Contributions: Conceptualization, W.H., Methodology, W.H., K.H., and M.H.; Software, A.W. and B.G.; Validation, W.H.; Formal analysis, D.C., Y.W., and Q.G.; Investigation, K.H., M.H., X.Z., and J.Y.; Resources, W.H.; Data curation, K.H., Y.W., Q.G., and X.Z.; Writing—original draft preparation, K.H., and M.H.; Writing一review and editing, W.H.; Supervision, W.H.; Project administration, W.H.; Funding acquisition, W.H.

Funding: This research was funded by the "Thirteenth Five-Year Plan" for National Key Research and Development Program (No. 2016YFD0400903) and National Natural Science Foundation of China (No. 31471923).

Conflicts of Interest: The authors declare no conflict of interest.

\section{References}

1. Lobo, V.; Patil, A.; Phatak, A.; Chandra, N. Free radicals, antioxidants and functional foods: Impact on human health. Pharmacogn. Rev. 2010, 4, 118-126. [CrossRef] [PubMed]

2. Pelicano, H.; Carney, D.; Huang, P. ROS stress in cancer cells and therapeutic implications. Drug Resist. Updat. 2004, 7, 97-110. [CrossRef] [PubMed]

3. Phaniendra, A.; Jestadi, D.B.; Periyasamy, L. Free radicals: Properties, sources, targets, and their implication in various diseases. Indian J. Clin. Bioche. 2015, 30, 11-26. [CrossRef] [PubMed]

4. He, F.; Zuo, L. Redox Roles of Reactive Oxygen Species in Cardiovascular Diseases. Int. J. Mol. Sci. 2015, 16, 27770-27780. [CrossRef] [PubMed]

5. Griffiths, K.; Aggarwal, B.B.; Singh, R.B.; Buttar, H.S.; Wilson, D.; De Meester, F. Food antioxidants and their anti-inflammatory properties: A potential role in cardiovascular diseases and cancer prevention. Diseases 2016, 4, 28. [CrossRef] [PubMed]

6. Manoharan, S.; Guillemin, G.J.; Abiramasundari, R.S.; Essa, M.M.; Akbar, M.; Akbar, M.D. The role of reactive oxygen species in the pathogenesis of Alzheimer's disease, Parkinson's disease, and huntington's disease: A mini review. Oxid. Med. Cell. Longev. 2016, 2016, 1-15. [CrossRef] [PubMed]

7. Jiang, T.; Sun, Q.; Chen, S. Oxidative stress: A major pathogenesis and potential therapeutic target of antioxidative agents in Parkinson's disease and Alzheimer's disease. Prog. Neurobiol. 2016, 147, 1-19. [CrossRef]

8. Umeno, A.; Horie, M.; Murotomi, K.; Nakajima, Y.; Yoshida, Y. Antioxidative and antidiabetic effects of natural polyphenols and isoflavones. Molecules 2016, 21, 708. [CrossRef] 
9. Zimmet, P.; Alberti, K.; Shaw, J. Global and societal implications of the diabetes epidemic. Nature 2001, 414, 782-787. [CrossRef]

10. Ogura, M.; Hori, M.; Harada-Shiba, M. Association Between cholesterol efflux capacity and atherosclerotic cardiovascular disease in patients with familial hypercholesterolemia. Arterioscler. Thromb. Vasc. Biol. 2016, 36, 181-188. [CrossRef]

11. Brown, M.; Goldstein, J. Multivalent feedback regulation of HMG CoA reductase, a control mechanism coordinating isoprenoid synthesis and cell growth. J. Lipid Res. 1980, 21, 505-517. [PubMed]

12. Carbonell, T.; Freire, E. Binding thermodynamics of statins to HMG-CoA reductase. Biochemistry 2005, 44, 11741-11748. [CrossRef] [PubMed]

13. Kiortsis, D.N.; Filippatos, T.D.; Mikhailidis, D.P.; Elisaf, M.S.; Liberopoulos, E.N. Statin-associated adverse effects beyond muscle and liver toxicity. Atherosclerosis 2007, 195, 7-16. [CrossRef] [PubMed]

14. Suntar, I.; Khan, H.; Patel, S.; Celano, R.; Rastrelli, L. An overview on citrus aurantiuml.: Its functions as food ingredient and therapeutic agent. Oxidative Med. Cell. Longev. 2018, 2018, 1-12. [CrossRef] [PubMed]

15. Shen, C.Y.; Jiang, J.G.; Huang, C.L.; Huang, C.L.; Zhu, W.; Zheng, C.Y. Polyphenols from blossoms of Citrus aurantium L. var. amara Engl. show significant anti-complement and anti-inflammatory effects. J. Agric. Food Chem. 2017, 65, 9061-9068. [CrossRef] [PubMed]

16. Karimi, E.; Oskoueian, E.; Hendra, R.; Jaafar, H. Phenolic compounds characterization and biological activities of Citrus aurantium bloom. Molecules 2012, 17, 1203-1218. [CrossRef] [PubMed]

17. Shen, C.Y.; Wang, T.X.; Zhang, X.M.; Jiang, J.G. Various antioxidant effects were attributed to different components in the dried blossoms of Citrus aurantium L. var. amara Engl. J. Agric. Food Chem. 2017, 65, 6087-6092. [CrossRef] [PubMed]

18. Yang, L.; Cao, Y.L.; Jiang, J.G.; Lin, Q.S.; Chen, J.; Zhu, L. Response surface optimization of ultrasound-assisted flavonoids extraction from the flower of Citrus aurantium L. var. amara Engl. J. Sep. Sci. 2010, 33, 1349-1355. [PubMed]

19. Shen, C.Y.; Wang, T.X.; Jiang, J.G. Extraction optimization and adsorption isotherm kinetics of polyphenols from blossoms of Citrus aurantium L. var. amara Engl. Sep. Sci. Technol. 2019, 1-10. [CrossRef]

20. Ballard, T.S.; Mallikarjunan, P.; Zhou, K.; O'Keefe, S. Microwave-assisted extraction of phenolic antioxidant compounds from peanut skins. Food Chem. 2010, 120, 1185-1192. [CrossRef]

21. Chemat, F.; Rombaut, N.; Sicaire, A.G.; Meullemiestre, A.; Fabiano-Tixier, A.S.; Abert-Vian, M. Ultrasound assisted extraction of food and natural products. Mechanisms, techniques, combinations, protocols and applications. A review. Ultrason. Sonochem. 2017, 34, 540-560. [CrossRef] [PubMed]

22. Esclapez, M.D.; García-Pérez, J.V.; Mulet, A.; Cárcel, J.A. Ultrasound-assisted extraction of natural products. Food Eng. Rev. 2011, 3, 108-120. [CrossRef]

23. Bamba, B.S.B.; Shi, J.; Tranchant, C.C.; Xue, S.J.; Forney, C.F.; Lim, L.T. Influence of extraction conditions on ultrasound-assisted recovery of bioactive phenolics from blueberry pomace and their antioxidant activity. Molecules 2018, 23, 1685. [CrossRef] [PubMed]

24. Turrini, F.; Boggia, R.; Leardi, R.; Borriello, M.; Zunin, P. Optimization of the ultrasonic-assisted extraction of phenolic compounds from Oryza sativa L. 'Violet Nori' and determination of the antioxidant properties of its caryopses and leaves. Molecules 2018, 23, 844. [CrossRef] [PubMed]

25. Gullian Klanian, M.; Terrats Preciat, M. Optimization of the ultrasound-assisted extraction of phenolic compounds from Brosimum alicastrum leaves and the evaluation of their radical-scavenging activity. Molecules 2017, 22, 1286. [CrossRef]

26. Yang, L.; Yin, P.; Fan, H.; Xue, Q.; Li, K.; Li, X.; Sun, L.; Liu, Y. Response surface methodology optimization of ultrasonic-assisted extraction of Acer truncatum leaves for maximal phenolic yield and antioxidant activity. Molecules 2017, 22, 232. [CrossRef] [PubMed]

27. Do, Q.D.; Angkawijaya, A.E.; Tran-Nguyen, P.L.; Huynh, L.H.; Soetaredjo, F.E.; Ismadji, S.; Ju, Y.H. Effect of extraction solvent on total phenol content, total flavonoid content, and antioxidant activity of Limnophila aromatica. J. Food Drug Anal. 2014, 22, 296-302. [CrossRef]

28. Chimuka, L.; Michel, M.; Cukrowska, E.; Buszewski, B. Influence of temperature on mass transfer in an incomplete trapping supported liquid membrane extraction of triazole fungicides. J. Sep. Sci. 2009, 32, 1043-1050. [CrossRef]

29. Naczk, M.; Shahidi, F. Extraction and analysis of phenolics in food. J. Chromatogr. A 2004, 1054, 95-111. [CrossRef] 
30. Belwal, T.; Dhyani, P.; Bhatt, I.D.; Rawal, R.S.; Pande, V. Optimization extraction conditions for improving phenolic content and antioxidant activity in Berberis asiatica fruits using response surface methodology (RSM). Food Chem. 2016, 207, 115-124. [CrossRef]

31. Feng, S.; Luo, Z.; Tao, B.; Chen, C. Ultrasonic-assisted extraction and purification of phenolic compounds from sugarcane (Saccharum officinarum L.) rinds. LWT-Food Sci. Technol. 2015, 60, 970-976. [CrossRef]

32. Luo, Y.; Peng, B.; Liu, Y.; Wu, Y.; Wu, Z. Ultrasound extraction of polysaccharides from guava leaves and their antioxidant and antiglycation activity. Process Biochem. 2018, 73, 228-234. [CrossRef]

33. Chemat, F.; Grondin, I.; Costes, P.; Moutoussamy, M.; Shum Cheong Sing, A.; Smadja, J. High power ultrasound effects on lipid oxidation of refined sunflower oil. Ultrason. Sonochem. 2004, 11, 281-285. [CrossRef] [PubMed]

34. Tiwari, U.; Cummins, E. Factors influencing levels of phytochemicals in selected fruit and vegetables during pre-and post-harvest food processing operations. Food Res. Int. 2013, 50, 497-506. [CrossRef]

35. Iqbal, D.; Khan, M.S.; Khan, A.; Khan, M.S.; Ahmad, S.; Srivastava, A.K.; Bagga, P. In vitro screening for $\beta$-hydroxy- $\beta$-methylglutaryl-CoA reductase inhibitory and antioxidant activity of sequentially extracted fractions of Ficus palmata Forsk. Biomed Res. Int. 2014, 2014, 1-10. [CrossRef] [PubMed]

36. Qin, H.Y.; Zhou, G.M.; Peng, G.L.; Li, J.P.; Chen, J.H. Application of ionic liquid-based ultrasound-assisted extraction of five phenolic compounds from Fig (Ficus carica L.) for HPLC-UV. Food Anal. Meth. 2015, 1673-1681. [CrossRef]

37. Goltz, C.; Ávila, S.; Barbieri, J.B.; Igarashi-Mafra, L.; Mafra, M.R. Ultrasound-assisted extraction of phenolic compounds from Macela (Achyrolcine satureioides) extracts. Ind. Crop. Prod. 2018, 115, 227-234. [CrossRef]

38. Seifzadeh, N.; Ali Sahari, M.; Barzegar, M.; Ahmadi Gavlighi, H.; Calani, L.; Del Rio, D.; Galaverna, G. Evaluation of polyphenolic compounds in membrane concentrated pistachio hull extract. Food Chem. 2019, 277, 398-406. [CrossRef]

39. Shen, Y.; Zhang, H.; Cheng, L.; Wang, L.; Qian, H.; Qi, X. In vitro and in vivo antioxidant activity of polyphenols extracted from black highland barley. Food Chem. 2016, 194, 1003-1012. [CrossRef]

40. Awe, F.B.; Fagbemi, T.N.; Ifesan, B.O.T.; Badejo, A.A. Antioxidant properties of cold and hot water extracts of cocoa, Hibiscus flower extract, and ginger beverage blends. Food Res. Int. 2013, 52, 490-495. [CrossRef]

41. Su, X.Y.; Wang, Z.Y.; Liu, J.R. In vitro and in vivo antioxidant activity of Pinus koraiensis seed extract containing phenolic compounds. Food Chem. 2009, 117, 681-686. [CrossRef]

42. Gulcin, I. Antioxidant activity of caffeic acid (3,4-dihydroxycinnamic acid). Toxicology 2006, 217, $213-220$. [CrossRef] [PubMed]

43. Soares, R.A.M.; Mendonça, S.; de Castro, L.Í.A.; Menezes, A.C.C.C.C.; Arêas, J.A.G. Major peptides from amaranth (Amaranthus cruentus) protein inhibit HMG-CoA reductase activity. Int. J. Mol. Sci. 2015, 16, 4150-4160. [CrossRef] [PubMed]

44. Lachenmeier, D.W.; Monakhova, Y.B.; Kuballa, T.; Löbell-Behrends, S.; Maixner, S.; Kohl-Himmelseher, M.; Waldner, A.; Steffen, C. NMR evaluation of total statin content and HMG-CoA reductase inhibition in red yeast rice (Monascus spp.) food supplements. Chin. Med. 2012, 7, 8. [CrossRef] [PubMed]

Sample Availability: Samples of CAB and total phenolic extract are available from the authors.

(C) 2019 by the authors. Licensee MDPI, Basel, Switzerland. This article is an open access article distributed under the terms and conditions of the Creative Commons Attribution (CC BY) license (http://creativecommons.org/licenses/by/4.0/). 